\title{
Propagación de garantías y jueces, la protección de los Derechos fundamentales: ¿convivencia o conflicto entre los sistemas constitucionales internacionales y regionales? Evolución de una década en España
}

\section{La multiplication des garanties et des juges dans la protection des Droits Fondamentaux: coexistence ou conflit entre les systèmes constitutionnels, internationaux et régionaux? Évolution d'une décennie en Espagne}

Recibido: 12/05/15 - Aprobado: 11/09/15

Marc Carrillo

Doctor en Derecho

Profesor Université Pompeu Fabra (España) marc.carrillo@upf.edu

\section{RESUMEN}

El presente artículo pretende dar a conocer el panorama del derecho constitucional español, por ello, en primer lugar presenta lo que fue para España el nuevo período democrático con el reconocimiento constitucional de una amplia gama de derechos y libertades y de un sistema judicial dotado de las salvaguardias que garantizan la protección de los derechos de las personas ante los tribunales, lo que se traduce en la primera señal del nuevo régimen político democrático, luego de que los mismos derechos y garantías fueran violadas continuamente por la dictadura franquista. Seguidamente, exhibe el pluralismo jurisdiccional existente, entendiendo con ello: i). Las condiciones para la aplicación de los derechos y libertades contenidas en dicho catálogo, y; ii). La división clave de competencias entre las diferentes jurisdicciones, jueces y organismos para proteger derechos fundamentales, con lo cual se logra llegar a la conclusión de que todos los derechos no están sujetos al mismo nivel de exigencia jurídica, a pesar de que existen dos cláusulas generales que son una herramienta para la interpretación de estos, la dignidad humana y el libre desarrollo de la personalidad.

\section{PALABRAS CLAVE}

Derecho Constitucional español, sistema judicial, derechos fundamentales, jurisdicción, competencia.

\section{ABSTRACT}

This article seeks to highlight the scene of Spanish constitutional law. Therefore, the first part presented wants to show the Spain's new democratic period with the constitutional recognition, of a wide range of rights and freedoms. And a gifted legal system Safeguards guaranteeing the protection of the rights persons before the 
courts, giving it as a result in the first sign of the new democratic political regime, after the same rights and guarantees were continually violated by the Franco dictatorship. Then, it was displaying the existing judicial pluralism, understanding thus: i). The conditions for the application of the rights and freedoms contained in the catalog ii). The key competence between different jurisdictions, judges and bodies to protect fundamental rights, which is achieved to conclude that all rights are not subject to the same level of legal requirement, although there are two general clauses division and they are a tool for the interpretation of these, human dignity and the free development of personality.

\section{KEYWORDS}

Spanish Constitutional Law, judiciary, fundamental rights, jurisdiction, competence.

\section{CONTENIDOYAPLICACIÓNDECATÁLOGOSDE PROTECCIÓN DERECHOS FUNDAMENTALES}

\section{A. CATÁLOgOS NORMATIVAS DE PROTECCIÓN DE LOS DERECHOS FUNDAMENTALES APLICABLES EN EL ORDENAMIENTO JURÍDICO INTERNO}

1. ¿Cuál es el contenido de los catálogos normativos aplicables ante el juez Constitucional $y$ ante los jueces encargados de la aplicación de estos derechos y libertades?

La incorporación de un catálogo específico en la Constitución Española (CE) de1978 era una opción política del otorgante. Por lo tanto, rechaza la alternativa que se limitaba al reconocimiento constitucional de los derechos de las primeras libertades a través de una remisión de la cláusula general a los tratados y acuerdos internacionales vigentes. La razón de esta elección fue que después de cuarenta años de dictadura, la Constitución como instrumento racional y normativo, no sólo tenía que reconocer la separación de poderes, sino que también debe incluir explícitamente una declaración de derechos y libertades propias. En este sentido, el Título 1 de la CE relativa a los derechos y libertades era como un signo de identidad de la oposición democrática en una dictadura.

Fue para iniciar el nuevo período democrático con el reconocimiento constitucional de una amplia gama de derechos y libertades, así como un sistema judicial dotado de las salvaguardias para garantizar la protección de los derechos en los tribunales. No hay que olvidar que los mismos derechos y garantías fueron violados continuamente por la dictadura franquista, por lo que su garantía constitucional se ha convertido en una primera señal del nuevo régimen político democrático.

Por lo tanto, la lista de los derechos establecidos en el Título 1 de la CE se concibió como un texto unitario aprobado en un solo acto legislativo. Así que no fue el resultado de un proceso gradual de sedimentación de los diversos instrumentos internacionales, a pesar de encontrar un poco de influencia del constitucionalismo español, especialmente la Constitución republicana anterior de 1931. Esto también plantea la cuestión de la pertinencia del derecho comparado, especialmente constituciones de Alemania (1949) e Italia (1947) y el Convenio Europeo de Derechos Humanos (1950).

La organización de derechos sistemáticos obedece a una estructura general que cumpla con la distinción clásica de los derechos públicos subjetivos, en función de su contenido material desarrollado por Jellinek. Así, en el ámbito de la libertad, que está protegida de las autoridades públicas (status libertatis), la Constitución Española reconoce derechos como el derecho a la vida, la libertad de religión y de creencias, el derecho a la libertad de movimiento y derechos de la personalidad (honor, intimidad), etc. En una segunda zona, están los derechos que permiten a los individuos requerir al Estado el respeto de sus derechos como ciudadanos (status civitatis). Entre ellos, se encuentran los derechos civiles y el derecho a un proceso regular de transporte (derecho a la protección judicial). En un tercer nivel son los derechos que permiten a los 
ciudadanos participar en el campo de la actividad política pública (status activae civitatis) para desarrollar sus derechos políticos: esto es particularmente el derecho de asociación política y el sufragio. Por último, en el cuarto nivel, que nunca fue la intención de Jellinek, hay derechos que requieren una acción positiva por parte del poder público (status positivus sociale). Estos derechos, como el derecho al trabajo o el derecho a la salud, permiten el reconocimiento de la situación social, económica y cultural.

Pero además de esta clasificación basada en el contenido material de los derechos, la CE también es compatible con otro sistema que se refiere a las garantías jurisdiccionales dados los diferentes derechos y libertades. Al respecto, hay que señalar que el carácter normativo de la Constitución española permite que todos los derechos sean objeto de la garantía legal ante los jueces y los tribunales. Sin embargo, todos los derechos no están sujetos al mismo nivel de exigencia jurídica. Los derechos fundamentales (es decir, los derechos a la libertad y la participación política) se benefician de un sistema de garantía judicial reforzada a través de los tribunales ordinarios, y si es necesario, mediante el recurso de amparo ante el Tribunal Constitucional (art. 53.2 $\mathrm{CE})$. Todos los demás derechos y libertades (derechos civiles y sociales) están garantizados por la jurisdicción ordinaria (art. 53.1 CE). Por último, los principios rectores de la política social y económica están garantizados por los tribunales ordinarios en los términos establecidos por la ley. Estos objetivos deben ser realizados por las autoridades públicas, pero no son directamente aplicables. Estas directrices carecen de efecto jurídico inmediato, la interposición de una ley es necesaria para capturar los tribunales ordinarios. Debe por lo tanto, una ley del Parlamento que contabilizar con certeza, los derechos subjetivos que fluyen principios, por ejemplo para establecer la condición social, económica y jurídica de la familia, el sistema jurídico público de la seguridad social, el derecho a la protección de salud, y el acceso a la cultura etc. Sin embargo, a pesar de la falta de efecto directo, son principios no programáticos porque su reconocimiento, su respeto y protección inspira no sólo el derecho positivo, sino también la práctica judicial y la actividad de los poderes públicos (art. 53.3 CE).

En cualquier caso, los derechos constitucionales fundamentales 0 no, exigen a todos los poderes públicos, independientemente de su función (legislativo, ejecutivo o judicial) 0 área territorial nacional, regional o local (Diez, 2002). Ellos tienen efecto vinculante sobre las relaciones entre los individuos, es decir, efecto interpretativos horizontal o interprivatos (Drittwirkung) (Bilbao, 1997). Este efecto vinculante para las autoridades públicas es inmediato, no necesita la intervención previa de la ley del Parlamento (STC 15/1982), consecuencia del carácter normativo de la Constitución. Cualquiera que sea la densidad de formulación semántica de la Constitución, los derechos constitucionales tienen una posición de supremacía sobre la legislatura. De hecho, la ley que regula el régimen jurídico debe siempre respetar su contenido esencial (art. 53.1 CE), es decir, el núcleo considerable de los derechos fundamentales de acuerdo con la opinión iuris, que identifica sus características básicas por lo que no está disponible para el legislador.

El contenido esencial de la cláusula se incorpora como una garantía objetiva de la influencia de la constitución alemana, pero de hecho, ha sido poco utilizada por la Corte Constitucional. En cualquier caso, si el legislador viola la Constitución, la garantía de protección la tiene el Tribunal Constitucional a través de la acción directa de inconstitucionalidad contra la ley. Además, es un derecho fundamental, la ley debe ser orgánica, y requiere la aprobación de la mayoría absoluta en el Congreso de los Diputados (artículo $81 \mathrm{CE}$ ).

Para completar el cuadro de los derechos reconocidos en la Constitución Española, es necesario añadir dos cláusulas generales que son una herramienta para la interpretación, esta son a la dignidad y al libre desarrollo de la personalidad (art. 10.1 CE). A diferencia de Alemania es un derecho fundamental en España, la dignidad de la persona no se reconoce como un derecho constitucional sino como un valor capaz de influir en los poderes públicos para una interpretación (SSTC 120/1990 y 91/2000). Por lo 
tanto, la Constitución da al Estado una dimensión axiológica en la garantía de los derechos y libertades, basada no sólo en la existencia de un sistema de garantías superdotadas jurisdiccionales, sino también una concepción moral de la persona en su condición de titular del derecho.

Además, el valor del libre desarrollo de la personalidad, importada también por la Ley de Bonn básica de 1949 se configura como un principio general de la libertad de la persona, que pone límites a la legislatura que no tiene poderes ilimitados para regular la libertad del individuo. En el mismo sentido, cualquier norma que prohíbe el principio de libertad debe cumplir el criterio de proporcionalidad (STC 93/1992, 15/ 1996).

\section{2. ¿Cuáles son las condiciones para la aplica- ción de los derechos y libertades contenidas en estos catálogos?}

a) Los derechos y libertades proclamados en el Título 1 de la Constitución Española se reconocen en algunos casos de las personas en general y en otros casos a ciudadanos en particular. En este sentido, la Constitución española ofrece áreas en el que el reconocimiento específico de los derechos es limitado. El más importante entre ellos es, sin duda, la relativa a los extranjeros:

i). Los extranjeros gozarán en España de las libertades públicas que garantiza el presente capítulo 1 , los términos que establezcan los tratados y la ley; ii). Los españoles sólo tienen derechos reconocidos en el artículo 23, excepto de acuerdo con el criterio de disposiciones de reciprocidad establecidos por tratado o ley sobre el derecho de sufragio activo y pasivo en las elecciones municipales (Art. 13. C.E).

Después de lo que se espera por la Constitución española y su interpretación por el Tribunal Constitucional (SSTC 115/1987 94/1993, 116/1993 y 242/1994 236/2007), los extranjeros residentes en España tienen derecho a una primer grupo de garantías en las mismas condiciones que los nacionales, los derechos inherentes a la dignidad de la persona (art. 10.1 CE). Por ejemplo, el derecho a la vida física, la integridad Psicológica la igualdad, la libertad de religión y de creencias, el derecho a la intimidad o el derecho a la tutela judicial efectiva. Un segundo grupo de derechos, sin embargo, pertenece exclusivamente a los ciudadanos españoles. Este es el derecho a la participación política y el acceso a las funciones públicas (art. $23 \mathrm{CE}$ ). El tercer grupo está formado por los otros derechos que los extranjeros pueden poseer. Sin embargo, las condiciones de su ejercicio serán determinados y se ponderará con la ley. Con respecto a este grupo de derechos, la jurisprudencia constitucional ha reconocido en ocasiones un legislador con amplia libertad para regular el ejercicio de los derechos fundamentales de los extranjeros en comparación con los nacionales.

Sin embargo, en relación con el régimen de los extranjeros en España, es necesario acreditar el carácter específico de los extranjeros que sean nacionales de Estados miembros de la Unión Europea. Al respecto, cabe señalar que la ciudadanía europea se adquiere por tener la nacionalidad de alguno de los Estados miembros de la UE. Por lo tanto, existe una doble relación, jurídica y política, la ciudadanía europea que implica el ejercicio de determinados derechos, tradicionalmente reservado a los nacionales. En España, los ciudadanos de la UE son tratados como españoles como titulares de derechos fundamentales a excepción de la participación política en las elecciones parlamentarias, regionales y referéndum.

Por último, otros casos que limitan la aplicación de los derechos contenidos en el catálogo del título 1 de la CE es, por ejemplo, el caso de los jueces y magistrados que se les impide el ejercicio del derecho de asociación política y la libertad de asociación (art. $1127 \mathrm{CE}$ ), al igual que a los miembros del Ejército. Por el contrario, es la propia constitución (art. 159.4 CE), la que reconoce un régimen diferente a los jueces de la Corte Constitucional, para que puedan ser miembros de partidos políticos, pero no se podrán exceder las cargas de responsabilidad.

La Constitución española está en el contenido normativo de los derechos y libertades de una regulación específica sobre la ley excepcional 
(artículos 55 y 116), que en algunos casos implica su suspensión. Este puede ser general (55.1 y 116 de la CE) o individual (art. 55.2 CE). La ley de excepción se expresa a través de la declaración de alerta de estado de emergencia o estado de sitio, el sistema legal está regulado por la Ley Orgánica 4/1981 de 1 de junio, entre estas tres situaciones excepcionales, la segunda y tercera se refieren a la suspensión de los derechos.

El derecho excepcionalmente responde con las siguientes características (artículo $116 \mathrm{CE}$ ). En primer lugar, tiene una limitación o en algunos casos una suspensión de los derechos y un cambio en la distribución de funciones entre los poderes ya que normalmente implica un aumento de los poderes del ejecutivo. Sin embargo, todas las situaciones de emergencia no permiten la disolución del Parlamento. Cuando las habitaciones no están en sesión, automáticamente deberán convocarse, 0 si se agota la legislatura, sus funciones son apoyadas por la Delegación Permanente de cada habitación. Por lo tanto, sea para garantizar el funcionamiento regular de los poderes constitucionales del Estado, la situación excepcional debe ser estrictamente temporal; sólo se aplica durante la crisis, respetando el marco constitucional. Entonces, su único objetivo es salir de la crisis, los poderes de emergencia no son ilimitados, el uso de estos poderes debe ser proporcional a la intensidad de la crisis. Por último, la ley de emergencia, al igual que cualquier ley que restrinja los derechos extraordinarios debe interpretarse restrictivamente (Cruz, 1984).

La alerta está diseñada para cuatro escenarios diferentes: i). Los desastres públicos, ii). Las crisis de salud; iii). Detener los servicios públicos esenciales, cuando no se pueden garantizar; y, iv). En situaciones de carencia de necesidades básicas. Lo cual no implica la suspensión de todos los derechos, pero si la limitación del ejercicio de algunos de ellos, por ejemplo, la libertad de movimiento, la posibilidad de requisa temporal de determinados bienes, el uso de los servicios, la intervención de algunas empresas, la movilización de la población, entre otros.
El estado de emergencia se prevé como un instrumento constitucional para responder a las crisis políticas que produzcan una grave perturbación del orden público interno, sin posible readmisión en el ejercicio de las facultades ordinarias. En este caso, pueden ser suspendidas: las garantías de libertad y seguridad personales, la inviolabilidad del domicilio y el secreto de las comunicaciones, la libertad de circulación y residencia, la libertad de expresión y de información a través de la el control administrativo previo, el derecho de reunión y manifestación, gracias también al procedimiento administrativo, el derecho de huelga.

La ley marcial es una medida extrema de defensa contra una importante crisis política que afecta a la identidad política del Estado contra la soberanía, la independencia del Estado y de su ordenamiento jurídico: la insurrección o un golpe de integridad territorial o constitucional, que no puede ser resuelta por otros medios. En este caso, puede ser suspendido, de los mismos derechos que en el caso de un estado de emergencia y las garantías de la persona detenida (la información sobre sus derechos, los motivos de la detención y la asistencia jurídica).

Por último, la Constitución Española también proporcionó para el caso específico de la suspensión de los derechos individuales. Este caso también muestra la influencia de la Ley Fundamental de Bonn (1949), de la ley especial antiterrorista que se incorporó más tarde en el Código Penal, previendo la suspensión de los derechos individuales en situaciones relacionadas con actividades terroristas y grupos armados. Los derechos fundamentales que pueden suspenderse son tres: (artículo 55.2 CE) la duración máxima de la detención preventiva es de 3 a 5 días, la inviolabilidad del domicilio y el derecho a la confidencialidad de las comunicaciones. La jurisprudencia constitucional ha establecido criterios de interpretación para prevenir el abuso de esta legislación (STC 199/1987). En este sentido, el artículo 55.2 de la Constitución española requiere control judicial y parlamentario de las decisiones. La jurisprudencia de la Corte Constitucional estableció que la prórroga de dos días de detención bajo custodia policial debe ser autorizada por el juez 


\section{B. CATÁlOGOS COMPLEMENTARIOS O AUXILIARES}

La Constitución Española no solo ha puesto en marcha su propio catálogo de derechos y libertades, sino que también proporcionó una cláusula de apertura del derecho internacional de los derechos humanos, a través del artículo 10.2: "Las normas relativas a los derechos fundamentales y las libertades públicas reconocidos en la Constitución se interpretarán de conformidad con la Declaración Universal de Derechos Humanos y los tratados y acuerdos internacionales ratificados por España». Esta cláusula debe interpretarse en relación con el art. $93 \mathrm{CE}$, que permite la incorporación del derecho internacional en el derecho español:

La ley orgánica podrá autorizar la celebración de tratados que atribuyen a la organización o institución internacional el ejercicio de competencias derivadas de la Constitución. Corresponde a las Cortes Generales (Parlamento) o el Gobierno, en su caso, para garantizar el cumplimiento de estos tratados y resoluciones de organismos internacionales 0 supranacionales beneficiarios de esta transferencia de competencias (art. $93 \mathrm{CE}$ ).

Por lo tanto, más allá del simple catálogo de derechos y libertades, las declaraciones internacionales de derechos humanos son un complemento hermenéutico que permite la interpretación judicial de los derechos en virtud del derecho internacional de los derechos humanos incorporados a la legislación española. En este sentido, las disposiciones constitucionales citadas hacen hincapié en la dimensión internacional del Estado, que tiene efecto no solo en el Parlamento y los estándares del gobierno en cuanto a la función jurisdiccional de los tribunales, sino también en la Corte Constitucional. Al respecto, hay que señalar que es común el uso, como los argumentos legales para ambos tribunales constitucionales ordinarios, las referencias propuestas por el Tribunal Europeo de Derechos Humanos, en particular, así como por el Tribunal de Justicia de la Unión Europea, para interpretar o, si es necesario, complementar el contenido del derecho reconocido en el catálogo constitucional.
No obstante, es importante señalar que la cláusula inicial de art. 10.2 de la Constitución española no se atribuyó a los tratados internacionales el valor de las normas constitucionales. De hecho, la jurisprudencia consolidada les ha concedido sólo un valor interpretativo y complementaria (STC 64/1991, el caso Apesco).

Por lo tanto, la violación de un tratado no siempre significa la violación de la Constitución. Sin embargo, el caso español es especialmente sensible toda vez que referencia al Convenio Europeo de los Derechos Humanos de 1950 y la adopción de criterios jurídicos del Tribunal de Estrasburgo (TEDH). Por lo tanto, el Tribunal Constitucional dictaminó que cuando la CEDH establece la violación de la ley, el resultado también incluye una violación del derecho garantizado por la Constitución española, que necesita ser reparado en la legislación nacional (STC 245/ 1991, caso Bultó).

Del mismo modo, hay que señalar que la adhesión de España a la Unión Europea ha también afectado la garantía de ciertos derechos fundamentales. El Tribunal Constitucional ha reconocido el derecho comunitario como norma de interpretación del catálogo de los derechos de Título I, con las disposiciones interpretativas del arte (10.2 CE). En el mismo sentido, en cuanto a la carta de los Derechos Fundamentales de la Unión Europea, el Tribunal otorgó valor interpretativo de los derechos fundamentales (STC 53/2002).

\section{EL PLURALISMO JURISDICCIONAL}

\section{A. ¿Cuáles son los jueces, tribunales y / o los organismos competentes que garanticen la protección de los derechos fundamentales?}

La garantía de los derechos y libertades envuelve sustancialmente a los órganos del poder judicial (artículo $53 \mathrm{CE}$ ). Es decir, los tribunales ordinarios son los propios jueces de la protección de los derechos humanos en España y no el Tribunal Constitucional (Carrillo, 1995). Es con los tribunales ordinarios que pueden reclamar el derecho a la protección judicial (artículo $24 \mathrm{CE}$ ), es decir, el acceso 
a Juez ordinario predeterminado por la ley, el derecho a un procedimiento judicial, de conformidad con las garantías judiciales y el derecho a un juicio razonado.

Pero en el sistema español, al igual que en Alemania, el recurso de amparo es parte del sistema de salvaguardias (art. 53.2 CE). Esta es una manera extraordinaria en la que la solicitud es subsidiaria al procedimiento judicial ordinario. Sin embargo, el amparo no es una garantía que se aplica a todos los derechos constitucionales, pero sólo a los que, de acuerdo con la Constitución Española, tiene la condición de los derechos fundamentales (art. 14 y los derechos conjunto en la sección I del capítulo II del Título 1: los derechos de la libertad y de los derechos políticos y la participación).

De acuerdo con lo anterior, a través de la provisión para la apertura del Derecho Internacional (artículo 10.2), la Constitución permite el acceso individual a un proceso europeo de los derechos humanos internacionales regionales ante el Tribunal Europeo de Derechos Humanos, una vez agotados los recursos internos. También es importante destacar la garantía indirecta ofrecida por el Tribunal de Justicia de la Unión Europea. Aunque el ciudadano no tiene legitimación directa para acceder a este órgano judicial de la UE, no hay duda de que su jurisprudencia relativa a determinados derechos y libertades reguladas por la legislación europea, es una garantía adicional para el ciudadano español. Especialmente por medio de la pregunta preliminar.

Además de las garantías legales, la Constitución Española también proporciona un conjunto de garantías no judiciales. Esto se aplica en primer lugar, al Defensor del Pueblo (Ombudsman o Defensor del Pueblo, art. 54 CE), al Alto Comisionado del Parlamento actuando bajo poder judicial como persuasiva para garantizar los derechos y libertades en el caso de los pobres administraciones y gestiones de los organismos públicos; luego están los gobiernos independientes, que son reguladores de sectores específicos de la administración pública, con personalidad jurídica, así como la autonomía orgánica y funcional. En la actualidad, se agrupan en una sola institución llamada la Comisión Nacional de los mercados y de la competencia (Ley $3 / 2013$, de 4 de junio), quien ejerce sus funciones con el objetivo de preservar y promover la competencia efectiva en todos los mercados productivos, es decir, en el mercado de las comunicaciones electrónicas, el mercado de la electricidad y el gas natural, el mercado postal y el mercado Comunicación Audiovisual, las tasas aeroportuarias y la industria ferroviaria.

\section{B. ¿Hay una división clave de competencias entre las diferentes jurisdicciones, jueces y organismos para proteger derechos fundamentales?}

a) La pregunta más relevante en este sentido es relativa a la relación entre la justicia ordinaria y el Tribunal Constitucional. La garantía de los derechos y libertades de los dos tribunales se llevan a cabo no por razones basadas en la competencia material, si no están de acuerdo con criterios formales, es un decir, por el carácter subsidiario de apelación individual de amparo ante el Tribunal Constitucional. Esto significa que la remisión sólo es posible si previamente se han agotado todos los recursos ante los tribunales ordinarios, pero la persona que llama ha obtenido la satisfacción de sus intereses.

Después de la reforma de $2007^{1}$, el procedimiento para la admisión de las acciones individuales (amparo) ante el Tribunal Constitucional es de especial interés, el artículo 50.1 b) de la Ley Orgánica del Tribunal Constitucional (LOTC) establece un requisito previo más importante para la comprensión de la relación entre la justicia ordinaria y la propia Corte Constitucional:

El recurso de amparo será objeto de una decisión de admisibilidad. La Sección ha de decidir por unanimidad por fin sin dar razones (Providencia) la

1 La reforma de la Ley Orgánica del Tribunal Constitucional por la Ley Orgánica 6/2007del 24 de mayo, que modifica la Ley Orgánica 2/1979 sobre la Corte Constitucional. 
admisión del recurso, en todo o en parte, pero sólo cuando se llenen los siguientes requisitos:

B) el contenido del recurso justifica una decisión sobre el fondo por parte del Tribunal Constitucional, por su especial trascendencia constitucional, que será evaluada en relación a su importancia, en su aplicación o por su eficacia General, y para determinar el contenido y alcance de los derechos fundamentales.

El nuevo procedimiento de admisión significa la objetivación de amparo. La reforma de 2007 no sólo se reduce la carga sobre los temas constitucionales que quedan por resolver, sobre todo se ha mantenido para cambiar el diseño de esta práctica institucional desarrollada por la Corte Constitucional para recuperar el sentido procesal especial y recurso extraordinario de amparo individual. El formato de la prórroga era una reforma del procedimiento que actúa sobre el proceso de admisibilidad (Aragón, 2009). En este sentido, el legislador rechazó otras soluciones más radicales que condujeron necesariamente a la modificación de la Constitución, como fue el caso de la supresión de la apelación, o incluso reducir su ámbito material.

Por lo tanto, la reforma fue diseñada para: i). Fortalecer el papel de los tribunales ordinarios como la sede natural o habitual de la garantía de los derechos fundamentales; ii). Del mismo modo, dedicar la aplicación individual como una referencia extraordinaria en comparación con derechos de tutela ordinaria que devuelve a la justicia ordinaria; y iii). Llevando a este objetivo, se tuvo que cambiar la ruta de entrada de los ciudadanos a la Corte Constitucional. En otras palabras, los criterios de elegibilidad tuvieron que ser cambiados.

b) La dirección de la reforma. Ab initio, esta reforma no puede ser entendida como una especie de prescripción de la garantía legal de los derechos fundamentales por parte de la Corte Constitucional. La lógica de las reformas contenidas en la nueva redacción del artículo 50 de la LOTC, se centró en el establecimiento de un criterio que formule positivamente a juzgar la admisibilidad de la remisión y así mismo, sobre la objetivación de amparo y fortaleci- miento de la jurisdicción ordinaria a través de un rediseño de la prueba de los hechos (art. 241.1 Ley Orgánica 6/1985, de 1 de julio, del Poder Judicial).

Sobre la admisibilidad del juicio formulado positivamente se debe dar más espacio a la decisión de la Corte Constitucional para evaluar la importancia de la aplicación individual de amparo constitucional y en última instancia para determinar o seleccionar cuál de ellos merece la pena continuar sobre el fondo, de acuerdo con la lógica de la objetivación de las razones de la solicitud, ya que es evidente que las razones jurídicas planteadas en el recurso de amparo no requieren del Tribunal. Este cambio de los criterios de elegibilidad ha aumentado los temores de que la reforma realmente ha dado un grado excesivo de la libertad, que llevó discreción por parte del Tribunal Constitucional (Ramos, 2010).

Por supuesto, la naturaleza de la reforma podría provocar alguna perturbación en la política judicial de la Corte, en su posición de competencia de la libertad había señalado Cappelletti. El fortalecimiento de la posición de los tribunales ordinarios de la protección de los derechos fundamentales, debe llevar al Tribunal a pronunciarse sobre un gran desafío, con la experiencia de la jurisprudencia constitucional durante casi treinta años, en el que el Tribunal Constitucional tiene que actuar dado que el número de recursos con relevancia constitucional debe reducirse mucho. Todo esto debe implicar un cambio significativo en la cultura de la Corte Constitucional, pero no está seguro de que todos ellos son ya bastante listos para tal objetivación (Carrillo, 1998).

Un cambio también debe asignar abogados para redactar las reivindicaciones de la defensa, que deben tratar de justificar la dimensión constitucional de sus argumentos. Esto requiere una mayor comprensión de la importancia de la Constitución como norma jurídica superior del ordenamiento jurídico y la jurisprudencia de la Corte Constitucional. En cualquier caso, se trata de un cambio de procedimiento inevitable, que se espera implementar un criterio jurídico constitucional, lo que requiere el máximo rigor en el razonamiento para detectar la existencia de relevancia constitucional, de acuerdo 
con parámetros objetivos que la reforma trae. Esta nueva cultura judicial también debe tener un impacto en el ámbito de la organización interna y los métodos de trabajo. Al respecto, cabe señalar que en un futuro próximo las sentencias de amparo, que hasta ahora han sido proferidas por las secciones y salas, deberán ser proporcionadas por el Tribunal en su conjunto, que tendría jurisdicción para decidir la apelación individuo.

c) La validez constitucional de la reforma. La modificación del procedimiento de admisión y la objetivación del amparo es una opción legislativa legítima. El artículo 53.2 de la Constitución no impide un modelo explícitamente de amparo, con esto queremos decir que esta garantía particular de los derechos fundamentales excluye una concepción objetiva. Lo que se estableció en la práctica implica una concepción subjetiva de petición individual. Pero no hay razón suficiente para concluir que la objetivación de la petición individual queda prohibida por la Constitución o que puede tener el peligro de reducir la protección efectiva de los derechos fundamentales.

Sin embargo, hay buenos argumentos para apoyar la posición contraria (Carrillo, 1998). Por lo tanto, es cierto que a partir de la interpretación literal del artículo 53.2 CE el amparo está concebido como una garantía judicial subjetiva de los derechos fundamentales. Pero la elección de legislador orgánico, que se manifiesta por los requisitos del procedimiento de admisión de un recurso basado en la objetivación del sujeto de la queja, no ofrece una contradicción radical con las disposiciones constitucionales. Es cierto que cuando la Constitución española define los criterios de calidad para iniciar la acción de amparo, se refiere a «cualquier persona física o jurídica que invoque un interés legítimo (...)» (Artículo 162.1 b CE). Esto podría llevar a argumentar que la garantía de los derechos fundamentales de la demandante, a través de este extraordinario camino, todavía se enfrenta a una gira que exige la protección del interés legítimo invocado por el apelante. Sin embargo, esta no es la única opción; especialmente debido a que el Tribunal Constitucional no tiene competencia para decidir sobre los asuntos relacionados con el derecho común, sólo puede actuar en el campo de la constitucionalidad. En este sentido, la sede natural de la protección de los intereses legítimos del solicitante y subjetiva sobre los derechos fundamentales está en la justicia ordinaria (Carrillo, 1995).

d) El déficit de la reforma. No obstante, es cierto que la reforma tiene un déficit que debe ser llenado. En concreto, esto se debe a la falta de preparación para el caso excepcional, o la demandante invoca violaciones particularmente graves que requieren atención inmediata del Tribunal (por ejemplo, en caso de comisión de un delito de tortura). En este sentido, hay que recordar que lo previsto por la reforma del art. 93. a.2 b) de la Ley de 1993 sobre el Tribunal Constitucional Federal de Alemania, cuando se establece que toda violación de un derecho fundamental justifica la admisión de la apelación (Verfassungsbwescherde). Para ser admitido a la convocatoria, el procedimiento establece que la violación de este derecho debe ser «grave y especial». Por lo tanto, tiene al mismo tiempo una dimensión objetiva y subjetiva.

e) La interpretación de la admisibilidad por el Tribunal. La sentencia del Tribunal Constitucional 155/2009 fue la interpretación judicial de la cláusula «por su especial trascendencia constitucional» del artículo 50.1.b) LOTC en el uso de la etapa de admisibilidad. La consecuencia de esta interpretación lleva de alguna manera a la aplicación de la regla de auto de avocación en el proceso de toma de decisiones de la Corte en una manera que parece acercarse al modelo implementado por la Corte Suprema de los Estados Unidos. En este sentido, el contenido material de la nueva regulación sobre los nuevos requisitos de admisión de las solicitudes individuales también muestra la influencia ejercida por el (Verfassungsbeschwerde) en Alemania desde su reforma en noventa años. La conclusión que se permite por un lado destacar el importante papel que asciende a los tribunales ordinarios en la tutela de los derechos fundamentales; y en segundo lugar, debería permitir a la Corte Constitucional para recuperar su papel de garantía legal extraordinario y subsidiario.

El balance que podemos hacer en la aplicación de la reforma de la Ley Orgánica 6/2007, del 24 de mayo 
estuvo condicionada por el impacto causado en el funcionamiento institucional de la Corte Constitucional (Ramos, 2010), el proceso traumático Dü STC $31 / 2010$ de 28 de junio sobre la reforma del Estatuto de Autonomía de Cataluña. El tiempo dedicado a los recursos contra esta norma (casi cuatro años) y los actos institucionales y políticos que rodeaban las actividades de la Corte, han provocado una desaceleración en su obra (Villaverde, 2002).

Para evaluar el impacto de la reforma de la acción de amparo, hay que centrarse en la decisión del Tribunal que se produjo después de la sentencia, y no antes. Según las estadísticas Tribunal de memoria en 2012 , se ha producido una cierta reducción de amparo que se presenta por los ciudadanos con respecto a años anteriores, pero en cualquier caso la vía del amparo es todavía una opción común que contrasta notablemente con las decisiones de admisibilidad resueltos por el tribunal: en 2012, en el juicio de admisibilidad fase sobre el fondo fueron admitidos 209 recursos de amparo, mientras que 7.341 solicitudes fueron rechazadas por orden sin dar razones (bienestar) .

Para evaluar, incluso la reforma provisional de 2007 , es fundamental tener en cuenta la sentencia $155 \mathrm{del}$ 25 de junio del 2009, el Tribunal ha establecido las reglas de interpretación que deben tenerse en cuenta en la evaluación del criterio de la especial «trascendencia constitucional», establecido por el art. 50.1 b) de la Ley Orgánica 6/2007 (Carrasco, 2001). La segunda base jurídica de la sentencia establece las siguientes reglas:

1. Cuando las ofertas de amparo ante un problema o una faceta de un derecho fundamental que debe ser garantizado y en la que no hay doctrina jurisprudencial.

2. Cuando el caso específico de la Corte da la oportunidad de aclarar o cambiar su doctrina tras un proceso de reflexión interna, la emergencia de nuevos cambios sociales o reglamentarios aplicables a la configuración del derecho fundamental, o debido a un cambio en la doctrina de los órganos de salvaguardia previstas en los Tratados y acuerdos internacionales.
3. Cuando la violación del derecho fundamental se deriva directamente de la ley u otra disposición de carácter general.

4. Si la violación del derecho fundamental tiene su origen en una interpretación judicial constante de la ley que la Corte considera perjudicial para el derecho fundamental y hace que sea necesario proclamar otra interpretación de la Constitución.

5. Cuando la doctrina del TC sobre la violación del derecho fundamental es ignorada en general y repetida por los tribunales ordinarios; o tiene la oportunidad de entrar en conflicto sobre el derecho fundamental o debido a una interpretación diferente de la doctrina constitucional, por la aplicación tardía o en algunos casos por la ignorancia de los demás.

6. En el caso de que un tribunal se niega de manera evidente de asentimiento a la doctrina de la Corte.

7. Por último, cuando la cuestión planteada no está incluida en ninguno de los casos descritos anteriormente, pero trasciende el caso particular, ya que plantea una cuestión jurídica importante y el impacto social y económico integral, o implicaciones políticas generales claras (sobre todo en el caso de amparo en materia electoral o los derechos de los parlamentarios) (sentencia 155/2009).

f) La reforma de los derechos fundamentales garantizados por los tribunales ordinarios, ciertamente para promover el éxito de la reforma de la acción de amparo, también se hicieron algunas reformas de la justicia ordinaria. Esta reforma, que a su vez debe permitir el pleno establecimiento del poder judicial como un «hábitat» natural para la garantía de los derechos y libertades, que seguirá siendo una fuente de problemas estructurales de la corte constitucional. En este sentido, se necesitan medidas adicionales para reformar la regulación del amparo que afecta a la protección de los derechos fundamentales por parte de los tribunales ordinarios. En el futuro inmediato, se reflexionará sobre las siguientes cuestiones 
en la reforma de la garantía judicial ordinaria de los derechos y libertades:

i) Se presentó la necesidad de establecer un procedimiento único y preferencial de la protección de los derechos fundamentales, independientemente de la jurisdicción o el caso, salvo los derechos que por su naturaleza requieren un procedimiento especial (derecho al habeas corpus, el derecho de reunión 0 de los aspectos del derecho al voto). Parece una diversidad razonable de los procedimientos existentes, establecidos de acuerdo con la naturaleza de la relación jurídica de los sujetos que entran en la controversia, a saber: un procedimiento especial para la protección de los derechos fundamentales en la ley de competencia administrativa, un procedimiento diferente en campo de trabajo, una ley orgánica de protección civil del derecho tiene la imagen personal y familiar honor, la intimidad y etcétera.

ii) La protección de los derechos fundamentales exige una acción rápida de los órganos del procedimiento. Los retrasos no pueden ser aceptados cuando los derechos fundamentales están en juego; la demora judicial es una amenaza para la calidad de la vida democrática. Esta diligencia jurisdiccional deberá ser suministrada por una sentencia definitiva sobre el fondo de la referencia. Pero la protección de los derechos fundamentales, no sólo está garantizada por la decisión final del juez, pero si es necesario, se proporciona a través de medidas cautelares (provisionales).

De acuerdo con esta lógica, la justicia interina consiste en un conjunto de medidas judiciales provisionales, el primer paso de la garantía de los derechos humanos. Por lo tanto, es necesario el desarrollo de diferentes tipos de medidas cautelares existentes en los procedimientos anteriores, la integración de las nuevas formas de protección temporal, y las medidas provisionales, posiblemente, incluso positivas, también con indicación de su contenido. En este sentido, dado el compromiso interpretativo tradicional de España con el texto de la ley requeriría la legislatura para definir mejor las medidas de precaución que deben tomarse. En particular, las relativas a las obligaciones de hacer 0 no hacer, especificando el alcance de los parámetros de interpretación habituales de la prima Bonni iuris, el peligro de la demora injustificada, también sin perder de vista la salvaguardia del interés público la seguridad jurídica del solicitante y el propio tribunal se beneficiarían.

La cuestión de inconstitucionalidad es una forma de revisión judicial sobre la ley aplicable a este caso. Esto ha permitido a la jurisdicción ordinaria participar en dicho control, en cooperación con los tribunales constitucionales en el juicio de constitucionalidad de la ley. De esta manera, los jueces y los tribunales han planteado ante el Tribunal Constitucional, varias preguntas sobre diversos temas (por ejemplo, la violación de los derechos fundamentales o la distribución de competencias entre el Estado y las Comunidades Autónomas), debido a la ley aplicable en este caso.

La cuestión de inconstitucionalidad es un procedimiento de control de objetivo específico de la ley. De hecho, es un control que, por su naturaleza o su finalidad, no es abstracto, sino algo concreto respecto a las razones de su enfoque, ya que su origen está relacionado con la cobertura de intereses subjetivos que se publicaron en el proceso principal ante los tribunales ordinarios. Se puede argumentar, según Cruz Villalón (1984) es una forma de revisión constitucional singular. En definitiva, la cuestión tiene un efecto, un valor adicional a la acción directa de inconstitucionalidad.

Este procedimiento ha mejorado la autonomía interpretativa de los jueces de la jurisdicción ordinaria, en la medida que ellos tienen la capacidad de hacer una interpretación constitucional de la ley. En este sentido, debe evocar en particular la frase de Calamandrei quien señaló que con la institucionalización de la cuestión previa de constitucionalidad, el juez ordinario abre la constitucionalidad de juicio. En este sentido, el incidente refuerza el papel institucional del juez en un Estado democrático. El principio de la independencia judicial adquiere una especial importancia para justificar un escrito que refuerza la posición autónoma de la torre de tribunales que está lejos de ser la norma de stare decisis. 
Con el recurso de inconstitucionalidad, se sentaron las bases para una difusión aceptable entre el Tribunal Constitucional y los tribunales ordinarios. Se puede decir que, en general, el tema ha sido una buena plataforma que familiariza al tribunal ordinario con el juicio de constitucionalidad y, asimismo, reitera su cultura jurídica de conformidad con las normas constitucionales y refuerza su educación democrática.

El asunto causó una colaboración entre los órganos judiciales en los esfuerzos interpretación especial de la ley, en consecuencia, de la Constitución. Ya se ha señalado que cuando el tribunal tiene serias dudas sobre la constitucionalidad de la ley aplicable en este caso, se planteará la cuestión de la justificación suficiente. Esto significa que el tribunal no puede limitarse a unos artículos genéricos, invocación afectada por la inconstitucionalidad de la ley impugnada o simplemente tomar los pecados de inconstitucionalidad planteadas por las partes en el procedimiento a quo. Más bien, la cuestión es tener jurisdicción ordinaria para mostrar, si es posible con una beligerancia legal especial, su poder de interpretar la disposición que ha sido asignado por la Constitución. En este sentido, se puede evitar invocación nominal argumentos erróneos y simplistas preceptos constitucionales. Las razones de inconstitucionalidad deben presentarse ante el Tribunal Constitucional y podrían tener un cuerpo argumentativo para resolver el problema, asimismo, debe ser el sustrato esencial para el diálogo jurídico necesario entre los tribunales.

\section{TRIBUNALES Y JURISPRUDENCIAS: PRO- GRAMACIÓN DE PLURALISMO}

a) La relación entre las garantías judiciales nacionales y supranacionales de derechos fundamentales es la cuestión de la situación jurídica de los tratados internacionales en el ordenamiento jurídico español (Diez, 2002). La Corte Constitucional consideró que, de conformidad con el artículo 10.2 CE, los tratados internacionales sobre derechos humanos suscritos por España son vinculantes para la interpretación de los derechos reconocidos en la Constitución (SSTC 38/1985, 36/1991, 254/1993, etc.). Así que cualquier juez ordinario al aplicar el derecho fundamental en un caso particular, deberá interpretarlo de acuerdo con los tratados internacionales. Sin embargo, el Tribunal Constitucional consideró que, en caso de conflicto entre la Constitución y el derecho internacional, no se pueden crear nuevos derechos.

Esto significa que la violación de un derecho en virtud de un tratado que no tiene equivalente en la Constitución no implica la inconstitucionalidad de las leyes y no plantea un recurso de amparo (SSTC 84 / 1989, $120 / 1990,28 / 1991$, etc.). Por lo tanto, si por un lado es evidente que los tratados internacionales de derechos humanos tienen valor interpretativo, por otro lado, hay que destacar que se pierde su propio sistema jurídico con el fin de la ley española (art. 53.1 CE).

Esta construcción jurisprudencial reduce el alcance derivado de la posición de los tratados en el ordenamiento jurídico (Art. 96.1 CE), establece que los tratados válidamente celebrados por España forman parte del ordenamiento jurídico español y que «sus disposiciones podrán ser derogadas, modificadas 0 suspendidas de lo dispuesto en los mismos o en conformidad con las normas de derecho internacional». Esto significa dos tratados formales en posiciones de supra-legalidad en el sistema legal, sin embargo, la jurisprudencia constitucional los neutraliza.

b) De acuerdo con el artículo $93 \mathrm{CE}$, la Constitución aparece como la base y el parámetro de la integración de la legislación europea en el ordenamiento jurídico español. De acuerdo con el texto:

Mediante la ley orgánica se podrá autorizar la celebración de tratados por los que se atribuya a una organización o institución internacional el ejercicio de competencias derivadas de la Constitución. Corresponde a las Cortes Generales o al Gobierno, según los casos, la garantía del cumplimiento de estos tratados y de las resoluciones emanadas de los organismos internacionales o supranacionales titulares de la cesión (Artículo $93 \mathrm{CE}$ ).

Por otra parte, el artículo 95 establece que:

1. La celebración de un tratado internacional que contiene disposiciones contrarias a la Constitución requiere la revisión previa de la Constitución. 
2. El Gobierno o cualquiera de las Cámaras pueden remitir al Tribunal Constitucional para que declare si existe o no esa contradicción.

Y, por último, el artículo 96.1 establece que:

Los tratados internacionales válidamente celebrados, una vez publicados oficialmente en España, formarán parte del ordenamiento interno. Sus disposiciones sólo podrán ser derogadas, modificadas o suspendidas en la forma prevista en los propios tratados o de acuerdo con las normas generales del Derecho internacional.

c) De conformidad con las disposiciones de los presentes Estatutos, el Tribunal Constitucional dictaminó que la Constitución es un límite a los tratados. Esto significa que, de acuerdo con la supremacía de la Constitución, los tratados de integración no pueden cambiar la Constitución. Por lo tanto, el proceso de integración no permite la adjudicación del poder constituyente a la Unión Europea (STC 252/ 1988 y la Declaración de la Corte Constitucional DTC$1 / 92$ y 1/2004).

Según DTC 1/2004, pronunciado con ocasión del Tratado que establece una Constitución para Europa, el Tribunal Constitucional declaró la transferencia de competencias a la Unión Europea, y por tanto, el proceso de integración posterior del Derecho europeo en el ordenamiento jurídico español, puede imponer límites a la soberanía estatal. Estos límites sólo serán aceptables en la medida en que el Derecho de la Unión es compatible con los principios fundamentales del Estado de los derechos sociales y democráticos establecidos por la Constitución. Estos límites físicos se derivan implícitamente de la Constitución. En particular, la Corte señaló que: «(...) El respeto de la soberanía estatal, nuestras estructuras constitucionales básicas y el sistema de valores y principios constitucionales consagrados en la Constitución, en el que los derechos humanos han adquirido un carácter distintivo» (art. 10.1 CE).

El proceso de integración europeo ha generado una «comunitarización» gradual del Derecho Constitucional español, y en este sentido, entre otros, los derechos y las libertades son un área en la integración europea muestra evidente. En concreto, el Tribunal Constitucional consideró pertinente tener legislación de la UE ya que este parámetro de evaluación en relación con los derechos humanos, a través de una cláusula de arte. 10.2 CE. Más tarde, tras la ratificación del Tratado de Lisboa por parte de España, a través de la Ley Orgánica 1/ 2008, por lo que el Parlamento ha ratificado el Tratado, estableciendo que: «\{...\} las normas relativas a los derechos y las libertades fundamentales que la Constitución ha reconocido que se interpretarán de conformidad con la Carta de los Derechos Fundamentales (CDFUE) publicado en el Diario Oficial de la Unión Europea de 14 de diciembre 2007».

El valor interpretativo del Derecho comunitario fue considerado por la Corte Constitucional en la STC $64 / 1991$. Los derechos que han sido afectadas por el valor hermenéutico del Derecho comunitario eran diferentes, especialmente los relacionados con el principio de legalidad de género, específicamente en el ámbito del contrato de trabajo (SSTC 12/2008 145/1991); Del mismo modo, ciertos derechos sociales de los ciudadanos de las personas de los países fuera de la UE (STC 120/1998); o garantía de indemnización en caso de despido por razones discriminatorias o en represalia por la afiliación al sindicato.

Pero la gran novedad de este año en la competencia de las garantías judiciales nacionales y supranacionales de derechos fundamentales sobre los derechos y los distintos niveles de protección, se dio principalmente en la sentencia del Tribunal Europeo de la Unión de Justicia (TJCE) del 26 de febrero 2013 relativa a la interpretación y la validez de la Decisión marco 2002/585/JAI del Consejo Europeo relativa a la orden de detención europea y a los procedimientos de entrega entre Estados miembros, en la nueva redacción dada por la Decisión marco 2009/299 / JAl. Como es sabido, la sentencia del TJCE deriva de una decisión de la Audiencia Nacional, un Tribunal español, que acordó el 12 de septiembre 2008 el descuento Stefano Melloni a las autoridades italianas para la realización de una condena impuesta por el Tribunal de Ferrara (Italia), en el marco de la llamada Decisión marco de la orden europea de detención y entrega. 
El señor Melloni ha apelado la decisión ante el Tribunal Constitucional español a través del procedimiento de amparo, sus argumentos fueron: la entregan a las autoridades italianas por el tribunal español implica una violación indirecta de las necesidades absolutas derivadas del derecho a la protección judicial (artículo 24.2 CE.), en la medida que socava el contenido esencial del derecho a un juicio justo de una manera que afecta a la dignidad humana, de modo que el acceso a la extradición en los países en los casos de infracciones muy graves, atribuyen su validez a la ausencia de una sanción penal, sin presentar que la rebaja que ha proporcionado el delincuente permite solicitar una revisión de la sentencia (conforme a lo dispuesto por la Legislación italiana) para proteger su derecho de defensa, lo que constituye una violación del derecho a un juicio con todas las garantías que deben acompañar a la misma.

No obstante, antes de resolver el amparo, la Corte Constitucional ha decidido, por primera vez plantear tres cuestiones prejudiciales al Tribunal de Luxemburgo, en la interpretación y validez del artículo 4 bis, apartado 1 Decisión marco 2002/584 / JAI. En la reformulación de 2009, el contenido de este artículo establece:

La autoridad judicial de ejecución, podrá denegar la práctica de la orden de detención europea a efectos del cumplimiento de una pena privativa de libertad 0 medida de seguridad cuando el acusado no compareció personalmente en juicio, a menos que:

- Él fue citado en persona e informado así de la fecha y lugar del juicio

- Se informó que la decisión podría ser emitida en caso de ausencia.

Teniendo en cuenta el juicio programado, se había dado un mandato a un abogado designado por él o, en su caso, por el Estado para defender en el juicio

Después de haber sido notificado de la decisión y de su derecho a un nuevo juicio

- Expresamente declaró que no pone en duda la decisión.
- No solicitó un nuevo juicio o no ha solicitado su revisión en el plazo establecido.

- No ha sido notificada de la resolución, pero:

- Él se comunicará de inmediato a la entrega y será informada expresamente de su derecho a un nuevo juicio o la capacidad de entrar de nuevo.

- Va a ser informado de la fecha en la que solicitará un nuevo juicio o que pudiera realizar la llamada.

Con motivo de la redacción de las tres preguntas, la Corte planteó la cuestión de las diferencias de nivel de protección del artículo 53 entre la legislación española en relación con la legislación italiana sobre el derecho a la protección judicial y el derecho al debido proceso reconocido por los artículos 47 y 48 de la Carta de los Derechos Fundamentales de la Unión Europea. Se debe tener en cuenta que, hasta ahora, la jurisprudencia española ha permitido el examen de una orden de detención y entrega, incluso cuando el preso no ha estado presente en el momento de la solicitud, mientras que la legislación procesal italiana niega esta posibilidad. Teniendo en cuenta estas diferencias obvias en nivel de garantía sobre el derecho de acceso a la justicia, el Tribunal Constitucional español remitió al apoderado del TJCE para que aprenda a ser intérprete del artículo 53 de la CDFUE, en el nivel de protección de los derechos garantizados por la Carta.

Respecto de las tres cuestiones sobre la interpretación y la validez del artículo 4 bis de la nueva decisión marco 1, el Tribunal de Justicia sostuvo que:

1. Debe interpretarse en el sentido, en los casos previstos por la decisión, que las autoridades judiciales ordenaron la ejecución de la orden de detención europea dictada para la ejecución de la pena impuesta en rebeldía, con la condición de que pueda ser revisado por el Estado miembro.

2. Esto es consistente con los requisitos establecidos en los artículos 47 y 48, párrafo 2 de la CDFUE. 
3. El artículo 53 de la CDFUE debe interpretarse en el sentido de que no permite a un Estado miembro la entrega de una persona condenada en rebeldía, a condición de que la sentencia puede ser examinada en el Estado miembro emisor, para evitar una violación del derecho a un proceso con todas las garantías y derechos consagrados en la Constitución.

Tras el examen de las preguntas formuladas por el Tribunal de Justicia, el Tribunal Constitucional, después de revisar su doctrina sobre la violación indirecta del derecho a un juicio con todas las garantías (STC 91/2000), decidió desestimar el recurso de amparo interpuesta por el Sr. Melloni (STC 26/ 2014).

La conclusión que permite alcanzar la doctrina establecida en el caso Melloni ha reducido el ámbito de aplicación de la teoría del constitucionalismo múltiple en relación con la garantía de los derechos fundamentales (Torres, 2009). Así, en la presente sentencia, el Tribunal de Justicia determinó que no es aceptable que el nivel de protección está sujeto a un doble nivel de protección cuando ya estaban prestados los avales por la legislación europea.

Sin embargo, la misma doctrina admite que uno puede aceptar un nivel diferente de protección que ha sido definido por la CDFUE, cuando se trata de medidas nacionales de aplicación de un acto de la Unión, a condición de que la solicitud no afecta al nivel de protección previsto en la carta, o podría afectar a la primacía del Derecho europeo.

La doctrina establecida en Melloni o Akerberg Fransson, pone de relieve la necesidad de fomentar el diálogo entre tribunal, a fin de evitar olvidar 0 negar catálogos de derechos básicos, para alcanzar un nivel básico de protección requerido en toda la Unión (Alonso, 2014). Este acto, en última instancia evita la confusión en el sistema europeo de protección de los derechos fundamentales.

\section{CONCLUSIONES}

Los derechos y libertades proclamados en el Título 1 de la Constitución Española se reconocen en al- gunos casos a las personas en general y en otros casos a ciudadanos en particular. En este sentido, la Constitución española ofrece áreas en el que el reconocimiento específico de los derechos es limitado. El más importante entre ellos es, sin duda, la relativa a los extranjeros; como quedo expresado, la ciudadanía europea se adquiere por tener la nacionalidad de alguno de los Estados miembros de la UE. Por lo tanto, existe una doble relación, jurídica y política, la ciudadanía europea implica el ejercicio de determinados derechos, tradicionalmente reservado a los nacionales.

A su vez, la Constitución Española no solo ha puesto en marcha su propio catálogo de derechos y libertades, sino que también proporcionó una cláusula de apertura del derecho internacional de los derechos humano, pues más allá del simple catálogo de derechos y libertades, las declaraciones internacionales de derechos humanos son un complemento hermenéutico que permite la interpretación judicial de los derechos en virtud del derecho internacional de los derechos humanos incorporados a la legislación española. Por lo tanto, la violación de un tratado no siempre significa la violación de la Constitución.

Sin embargo, el caso español es especialmente sensible toda vez que referencia al Convenio Europeo de los Derechos Humanos de 1950 y la adopción de criterios jurídicos del Tribunal de Estrasburgo (TEDH). Pues la Corte Constitucional consideró que, de conformidad con el artículo 10.2 $C E$, los tratados internacionales sobre derechos humanos suscritos por España son vinculantes para la interpretación de los derechos reconocidos en la Constitución (SSTC 38/1985, 36/1991, $254 / 1993$, etc.). Así que cualquier juez ordinario al aplicar el derecho fundamental en un caso particular, deberá interpretarlo de acuerdo con los tratados internacionales.

Entonces, la Constitución española establece en el contenido normativo de los derechos y libertades una regulación específica sobre la ley excepcional que en algunos casos implica la suspensión de algunos derechos, lo cual puede ser general 0 individual. 


\section{REFERENCIAS BIBLIOGRÁFICAS}

- Diez-Picazo Giménez, L. (2002). Sistemas de Derechos Fundamentales. Madrid. Thompson/ Civitas.

- Bilbao Ubillos J. (1997). La eficacia de los derechos fundamentales. Frente a los particulares, Centro de Estudios Políticos y Constitucionales, Madrid.

- Cruz Villalón P. (1984). Estados excepcionales y suspensión de garantías, Madrid.

- Carrillo M, (1995). La tutela de los derechos fundamentales por los tribunales ordinarios, Centro de Estudios Constitucionales, Madrid.

- Aragón Reyes, M. (2009). La reforma de la Ley Orgánica del Tribunal Constitucional. Revista Española de Derecho Constitucional.

- Ramos Hernández M. (2010). Admisión discrecional de los recursos de amparo por el Tribunal Constitucional. Balance de cuatro de aplicación del nuevo trámite de admisión, Revista de la Cortes Generales, p. 265.

- Villaverde Menéndez, I. (2002). Decidir qué no decidir o qué hacer con los amparos. El trámite de admisión de los recursos de amparo. Teoría y Realidad Constitucional $n^{\circ}$ 10-11, Madrid, pp. 323-365.

- Carrasco Duran M. (2001). El concepto constitucional del recurso de amparo: examen de posibilidades para una reforma de la regulación y la práctica del recurso de amparo. Revista española de Documentación Científica $n^{\circ} 63$. Madrid, pp. 79-127.

- Torres Pérez A. (2009). Conflictos de Derecho en la Unión Europea. Una teoría de la Adjudicación Supranacional. University Oxford Press.

- Alonso García R. (2014). El juez nacional en la encrucijada europea de los derechos fundamentales. Madrid .Real Academia de Jurisprudencia y Legislación.

- Garrorena Morales A. (1998). La Ley orgánica 6/ 2007 y la reforma del Tribunal constitucional. «Notas para una crítica», Tirant Lo Blanch, M. Carrillo. (Coord.) Hacia una nueva jurisdicción constitucional (Estudios sobre la Ley 6/2007 de 24 de mayo, de reforma de la LOTC), Valencia, p. 216-261

- Farreres Fernández G. (1998). La reforma de la Ley orgánica del Tribunal constitucional (Comentario a la Ley orgánica 6/2007, de 24 de mayo). M. Carrillo (Coord.) Hacia una nueva jurisdicción constitucional (Estudios sobre la Ley 6/2007, de 24 de mayo, de reforma de la LOTC), Valencia, pp. 148-149.

\section{PÁGINAS WEB}

- 7205 (2012); 7098 (2911); 8948 (2010); 10792 (2009); 10279 (2008). Memoria del Tribunal Constitucional 2012 (v. le sire du Tribunal: www. tribunalconstitucional.es). 